\title{
Origen de los espacios públicos en Valparaíso: el discurso higienista y las condiciones ambientales en el siglo XIX
}

\author{
Luis Álvarez Aránguiz
}

\section{Filiación}

Luis Álvarez Aránguiz, (c) Magister en Urbanismo, Universidad de Chile, Profesor del Instituto de Geografía de la Universidad Católica de Valparaíso y del Departamento de Arquitectura, Universidad Técnica Federico Santa María de Valparaíso. Cátedras de Geografía Urbana y Rural.

\section{Resumen}

Los Espacios Públicos en Valparaíso son producto de una domesticación paulatina del medio natural, dando origen a la habitabilidad de fines del s. XVI, las reservas de agua dulce y la explotación de la vegetación para obtener leña como energía, lo que determina la adecuación del paisaje original al menos durante dos siglos. El aumento de la población, y sus actividades, demandaron mayores volúmenes de recursos (agua y energía), obligando el desplazamiento y posterior degradación del espacio natural circundante. Este abandono, asociado a las condiciones de insalubridad fuertemente documentadas a fines del siglo XVIII, como plagas de parásitos, y las epidemias recurrentes a mediados del s. XIX, deterioró gravemente el ambiente ${ }^{1}$.

\section{Palabras clave}

Valparaíso, origen de los espacios públicos.

\section{Abstract}

The public spaces in Valparaíso are a result of a gradual taming of the natural environment, giving rise to habitability towards the end of the $16^{\text {th }}$ century, freshwater reserves and the exploitation of vegetation for firewood, thus determining the adaptation of the landscape during at least two centuries. The growth in population and activity demanded greater quantities of resources (water and energy), obliging the displacement and posterior degradation of the surrounding natural areas. This abandonment, associated with the well - documented unhealthy conditions such as

\footnotetext{
${ }^{1}$ Este artículo es un producto derivado de un trabajo de investigación mayor desarrollado por el autor en "Sistematización de los factores humanos, económico y físicos que concurren a la obsolescencia de los barrios de Valparaíso." Proyecto DGIP-UCV. Universidad Católica de Valparaíso. Dirección General de Investigación y Postgrado. 1993. En esta investigación concurren tres disciplinas; Arquitectura (Juan Mastrantonio F.), Historia (José de Nordenflicht) y Geografía, esta última desarrollada por el autor de este articulo; en este trabajo se logró organizar y superponer a través de tecnologías aplicadas, gran parte de la información espacializable de Valparaíso, escalando (cartas antiguas) y georeferenciando la información actual (tratamiento de fotografías aéreas). Si bien el objetivo principal de la investigación era el apoyo desde la Universidad de la postulación de la ciudad como "Patrimonio de la Humanidad", por parte de la UNESCO, se obtuvo valiosa y fructífera información que ha derivado en nuevas investigaciones y comunicaciones como la que aquí se presenta.
} 
plagues of parasites in the latter part of the $18^{\text {th }}$ and the recurring epidemics of the middle of the $19^{\text {th }}$ century, seriously deteriorated the environment.

\section{Key words}

Valparaiso, the origin of public spaces.

\section{Sumario}

Introducción

1.- Marco Teórico

2.-Análisis espacial

Conclusiones

Referencias

\section{Introducción}

Las condiciones de insalubridad de estos espacios naturales remanentes promueven la adaptación del discurso higienista europeo, que es difundido fuertemente en Valparaíso por don Guillermo Rawson. El concepto de una "ciudad higiénica" para ciudades puertos cosmopolitas como Valparaíso y Buenos Aires, está amparado en las ideas de las "topografías médicas" 2 y los planteamientos de urbanistas como Owen y Fourier ${ }^{3}$, fundamentalmente.

Esta difusión es producto de su inclinación por ver en la higiene un objetivo y también un recurso igualador, fundamento del Socialismo Romántico del s. XIX, que tendrá en Valparaíso alocuciones importantes por parte de Francisco Bilbao en el diario "La Gaceta del Comercio", antes de emprender viaje a Europa.

\section{Hipótesis}

Los Espacios Públicos de mayor significado urbano en Valparaíso tienen su origen en remanentes naturales. La constitución del asentamiento urbano original usufructuó de las condiciones naturales (Fig. No1), en especial de los cursos de agua y el borde costero. Su urbanización es producto de una subutilización de estos recursos que tiene

\footnotetext{
2 Por "Topografías Médicas" son conocidos los informes locales sobre las circunstancias de salubridad o insalubridad, utilizados por estudios de Geografía Médica desarrollados por médicos españoles durante el s. XIX, interesados por la higiene pública y su focalización espacial. El "higienismo" vincula directamente morbilidad y entorno, la prevención y la lucha contra las enfermedades, de modo particular las infecciones, se asentó sobre el conocimiento del entorno y de sus factores topográficos-médico locales. (ORTEGA, José, "Los horizontes de la Geografía; Teoría de la Geografía". Ariel Geografía, 2000 Barcelona.

${ }^{3}$ Las utopías sociales enmarcadas dentro del llamado "Socialismo Romántico" incidieron sobre los procesos constructivos de las ciudades europeas, la fuerza de la persuasión y de la divulgación ejercida por las teorías se debió en gran parte a la capacidad de formalizar las prefiguraciones sociales, piénsese en el "Falansterio" de Fourier el "Paralelogramo" de Owen o "Icaria" de Cabet. Son bien conocidas las vicisitudes que impulsaron a los utopistas europeos a elegir América como tierra prometida para la verificación de sus "réveries sociales" en GRAVAGNUOLO, Benedetto, "Historia del Urbanismo en Europa" 1750 - 1960. Akal Arquitectura 1998.
} 
como antecedente las primeras revoluciones sanitarias de la ciudad, como la construcción de acueductos y el equipamiento portuario, lo que se acentúa por un afán higienista y social, promovido a partir de la segunda mitad del siglo XIX.

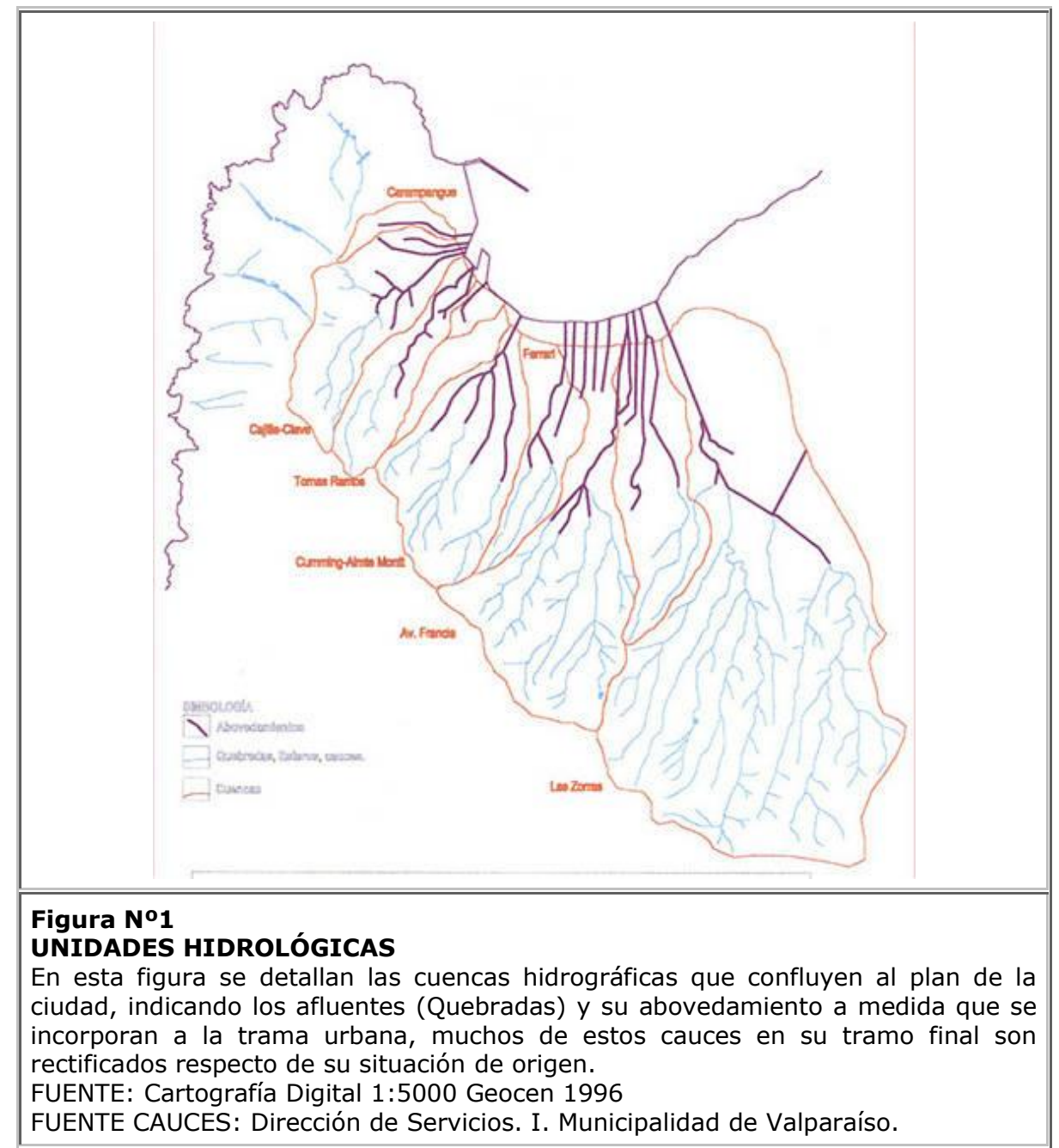

\section{1.- Marco Teórico}

\section{Higienismo}

El higienismo es una corriente de pensamiento desarrollada desde finales del siglo XVIII, animada principalmente por médicos. Partiendo de la consideración de la gran influencia del entorno ambiental y del medio social en el desarrollo de las enfermedades, los higienistas critican la falta de salubridad en las ciudades industriales, así como las condiciones de vida y trabajo de los empleados fabriles. 
En 1873 el naturalista Haeckel acuñaba la palabra "ecología" para referirse al estudio de las relaciones de los seres vivos con el ambiente físico y biológico; pasarían varias décadas antes de que el hombre ocupase el lugar central de los procesos ecológicos. Sin embargo, cien años antes de Haeckel, un grupo de médicos, los llamados higienistas, se habían planteado el problema del influjo del medio ambiente en la vida del hombre desde una perspectiva que anticipa los trabajos de ecólogos, geógrafos y urbanistas.

Dado que entre los higienistas está generalizada una concepción de la enfermedad como producto social, en los estudios de tipo epidemiológico es muy frecuente encontrar abundante información sobre el medio geográfico ${ }^{4}$, económico y social.

Vale la pena señalar que a lo largo del siglo XVIII se generalizarán dos teorías que, en la centuria siguiente, y unidas a las ideas que se expusieran antes, vendrán a constituir el eje teórico del paradigma de las topografías médicas ${ }^{5}$. Nos referimos a la doctrina miasmática y a las teorías sociales sobre la enfermedad.

\section{Sobre miasmas y emanaciones malignas}

En Italia, G. M. Lancisi (1654-1720), citado por Urteaga, L. (1980) ${ }^{6}$ recogiendo algunas ideas de los iatroquímicos del siglo anterior, sobre la "fermentación" de las aguas estancadas, concederá una importancia decisiva a los "vapores" emanados de los pantanos, a los que llamara "miasmas" en orden a establecer el origen de las epidemias. Las temperaturas elevadas de la época estival, producen una "destilación química" de las aguas pantanosas; los vapores, convertidos en efluvios volátiles, son trasladados por el viento, ocasionando diversos tipos de morbidez. A estos productos inorgánicos, se unen otros seres orgánicos producto de la descomposición, formando los enigmáticos "miasmas", que difundidos por la atmósfera afectarán al organismo humano.

\section{La miseria como reducto de enfermedades}

Por la misma época en que tienen gran consideración las doctrinas miasmáticas, se originan también aquellas interpretaciones de la enfermedad como fenómeno social, las que alcanzaron una amplia difusión en el siglo pasado. A finales del XVIII algunos médicos atribuirán a la pobreza, el exceso de trabajo, la mala alimentación, el hacinamiento en barrios insalubres, y otros factores de tipo económico-social, de gran relevancia para explicar el impacto de determinadas enfermedades.

\footnotetext{
${ }^{4}$ Fruto de esta actividad es una voluminosa literatura científica, Crf. Luis Urteaga "Miseria, miasmas y microbios. Las topografías médicas y el estudio del medio ambiente en el siglo XIX", en GEOCRITICA, Cuadernos Críticos de Geografía Humana, No 29, septiembre de 1980.

${ }^{5}$ Utilizamos aquí el término "paradigma" en el sentido más elemental de los propuestos por T. S. Kuhn. Un paradigma es un ejemplo o modelo del que surgen determinadas tradiciones de investigación científica. Tales modelos, que suministran el marco conceptual necesario a toda investigación, suelen proporcionar leyes, teorías y aplicaciones a los científicos que los aceptan (ver T. S. Kuhn, 1975, 34).

${ }^{6}$ Luis Urteaga Op. Cit.
} 
Nuestro país no estuvo ajeno a las grandes epidemias, registrándose para el siglo XIX, treinta y nueve eventos de esta naturaleza ${ }^{7}$, concentrándose fundamentalmente en pestes como la viruela, acompañada de escarlatina, cólera, tifus, fiebre amarilla. La más documentada para Valparaíso es la epidemia de Escarlatina de 1831-1832 ${ }^{8}$. En 1790, el médico vienés J. P. Frank (1745-1821), publica un folleto de expresivo título: La miseria del pueblo, madre de enfermedades". El enfoque "ecológico", que es el dominante en la literatura higienista durante gran parte del siglo XIX, es el sustrato teórico del paradigma de las topografías médicas. Este paradigma entra en crisis a fines del siglo XIX, los descubrimientos bacteriológicos permiten sentar sobre nuevas bases las explicaciones sobre el origen y naturaleza de las enfermedades contagiosas; lo que se ha llamado mentalidad etiopatológica ${ }^{10}$.

\section{Higienismo, Territorio, Ciudad}

Las investigaciones empíricas de tipo territorial son las Geografías y Topografías médicas. Bajo esta rúbrica, se realizaron desde finales del setecientos una serie de estudios de tipo geográfico-estadístico, en los que se insertan diversas consideraciones acerca del origen y desarrollo de las epidemias y sobre la morbilidad en general.

Estas monografías médicas suelen ceñirse a ciudades, localidades y comunas o regiones concretas, y tienen como base determinadas concepciones médicas, que consideran la génesis y evolución de las enfermedades como fuertemente determinadas por el clima y el medio local.

Desde el campo de la higiene, se tratan ampliamente además, problemas del espacio urbano, como la limpieza y la salubridad de las ciudades en su conjunto: esto repercutirá en la generación de Equipamientos e Infraestructura; a esto Valparaíso no estará ajeno, desarrollándose, por ejemplo:

\footnotetext{
7 Un completo y detallado libro sobre estos fenómenos de Epidemias. Epizootias, Plagas y hambruras, lo constituye el libro; cfr. Catástrofes en Chile 1541-1992, Rosa Urrutia de Hazbun. Carlos Lanza Lazcano. Editorial La Noria, Santiago, 1993.

8 ... A fines de 1831 apareció en Valparaíso una epidemia de escarlatina, lo que ayudó a que esto cundiera fue el desaseo de la población y la falta de higiene, a pesar de que se estructuraron las Juntas de Beneficencia y Salubridad; sólo en Santiago hasta donde alcanzó la epidemia se registraron para 1831 un total de 1.409 personas muertas y para 1832 un total de 3.013 personas muertas. En esa época sólo había nueve médicos en Santiago y cuatro en Valparaíso. En cfr. Urrutia de Hazbun, Rosa. Lanza Lazcano, Carlos. Op. Cit.

Una Carta de Diego Portales fechada en Valparaíso el 19 de enero de 1832, y dirigida a don Antinio Garfias en Santiago señala: .."la peste o fiebre escarlatina, parece que va desapareciendo en el puerto, aunque sigue en el Almendral, porque no para el sacramento, es la prueba que yo tengo más a la vista, porque siento las campanas de la Merced y una tambora que lo acompaña de noche y que no sé cómo no se ha hecho mil pedazos con tanto trajín... (recuérdese que los funerales son de noche) citado de Hernández, Roberto. op. Cit.

${ }^{9}$ Luis Urteaga Op. Cit.

${ }^{10}$ Luis Urteaga Op. Cit.
} 
- Servicios: mataderos ${ }^{11}$, alcantarillado, cementerios ${ }^{12}$ - Hábitat: poblaciones obreras, habitaciones

- Edificios públicos: hospitales, cárceles, templos

\section{Las tesis higienistas en Valparaíso}

La amenaza de la insalubridad es la verdadera impulsora del desarrollo de los conceptos higiénicos ${ }^{13}$, en la estructura física de la ciudad. En la acción local municipal se manifiesta a través de la "policía urbana", creada hacia 1830 con el objeto de materializar obras de saneamiento, operando sobre la infraestructura. Se construyen las redes de agua y alcantarillado, se adoquinan las calles y también se controlan las evacuaciones de las quebradas y cauces $\operatorname{cercanos}^{14}$, el control de los cursos de agua permite atrincherarlos y rellenarlos en las desembocaduras donde nacerán las vías y espacios públicos que albergarán las plazas y plazuelas de la ciudad.

Guillermo Rawson, de nacionalidad Argentina, (San Juan, Argentina 1821, París, 1890), Ministro de Interior durante la presidencia de Bartolomé Mitre, avecindado en Valparaíso y gran amigo de Chile, hacia 1850 es el difusor de los postulados higienistas en Valparaíso. En 1873 inauguró el Curso de Higiene de la Facultad de Medicina de la Universidad de Buenos Aires, sus postulados los refunde al final de su trayectoria

11 ... Respecto del consumo de la carne, la mejor pieza del animal no pasaba de un real, y no tenían dificultades con el matadero, sencillamente, porque tampoco había ninguno.. .(El Mercurio de Valparaíso, 12 de Dic. De 1827).

Sólo en 1843, la Municipalidad acordó la construcción de un matadero público, que, por diversas razones, sufrió no pocas demoras.

Claudio Gay, señala que cada individuo que tenía un animal y quería venderle al por menor, le mataba delante de la puerta de su casa... en las grandes ciudades esta operación se realizaba en patios en medio del lodo procedente del agua y de la sangre de los animales... estos después de estar lavados, los llevaban a lomos de caballo a la plaza de abastos o a las carnicerías llamadas pósitos. En: Hernández, R. C. 1927.

12 "... no hay reglamento que los quieren se entierran en el Panteón, pues los que mueren en el Hospital no van allá; y otros que por ser hermanos de algunas cofradías son enterrados en algún convento de regulares; también se dice, que los señores extranjeros tienen el privilegio de llevar sus cadáveres a su panteón de día, cuando para el de los hijos del país, solo se puede hacer desde las doce de la noche para adelante... en las actas municipales hay constancia que en Valparaíso se enterraba en las iglesias a las personas pudientes y que a los pobres de solemnidad se les enterraba en el campo. Muchos fueron los sitios destinados para la sepultación de cadáveres. En el cerro San Francisco, en la quebrada de san Agustín, en el cerro de concepción, en las Ramaditas, en la subida del cerro Barón y otros lugares existen todavía vestigios que prueban a lo que esas localidades estuvieron destinadas... solo en 1825 vino a disponerse la compra de los terrenos que ahora ocupan los cementerios 1 y 2.- (El Mercurio de Valparaíso, 17 de Noviembre de 1827).

13 ... El abandono más completo lo patentizan las calles hechas barrancas inmundas y el aire más insalubre en el que respiramos y amaga nuestra existencia de un modo directo, sin que se divise ni a lo lejos la terminación de tantos males, propias para que se desarrollase cualquier epidemia... EL MERCURIO DE VALPARAÍSO, 12 de Diciembre 1827.

${ }_{14}$.... cada hijo de vecino levanta su pared, fabrica un pretil y refacciona el daño que le ocasionó el temporal; sólo la ciudad, a quien le cedieron dos mil pesos para restablecer las pérdidas, hizo unos pocos puentes de madera en los principales zanjones por lo pronto, y por lo largo... En la plazuela de la Matriz y dentro de la plaza se han hecho dos pretiles de cal y piedra, sin consultar el derecho público. Don Manuel Blanco está empedrando la calle de los baratillos, aunque ahogue a los vecinos... En la quebrada de san Juan de dios, arbitrariamente se han hecho dos pretiles, sin consultar si es o no terreno propio; de suerte que a la vuelta de diez años todo debe ser edificios sin calles y sin bahía... EL MERCURIO DE VALPARAÍSO, 7 de Diciembre 1827. 
escribiendo el libro Observaciones sobre Higiene Internacional (1881). La calle lateral del Congreso Nacional en Valparaíso, lleva su nombre reemplazado hacia 1910, con motivo del Centenario de la Independencia.

El discurso igualador es desarrollado en Valparaíso por Francisco Bilbao ${ }^{15}$, quien se radica en Valparaíso antes de emprender viaje a Europa y coopera con la edición de la "Gaceta del Comercio" (1844) a la fecha, editado por su padre don Rafael Bilbao. En su recorrido por Francia (entre 1845-1850) conoció a Michelet, Quinet y Lamennais recogiendo las ideas del socialismo utópico.

La época en que Bilbao reside en París corresponde al período culminante del Romanticismo Social en Europa. En donde Carlos Fourier junto a Robert Owen y el conde Claude Henri Saint Simón someten a despiadadas críticas a la civilización en donde "la pobreza brota de la misma abundancia". Esto promueve el nacimiento de un urbanismo progresista donde Owen, Fourier, Considérant, Cabet y otros representantes de la corriente "Socialismo utópico" preconizan y difunden nuevas formas de asentamientos humano más perfectas, capaces de resolver los problemas creados por la urbanización galopante y de disolver la oposición campo y ciudad ${ }^{16}$.

\section{2.-Análisis espacial}

\section{Condiciones y procesos ambientales del soporte original ${ }^{17}$}

El "Puerto" tiene una data inmemorial por haber sido prospectado ya en la expedición de Almagro en 1536; Juan de Saavedra opta en sus recaladas por aquellos espacios protegidos con orientación norte, que lo salvaguardaba del viento sur predominante.

Por una disposición latitudinal; $33^{\circ}$ Lat. Sur, y una condición geomorfológica consistente en una ladera occidental (barlovento) de la Cordillera de la Costa desplazada hacia el norte, es posible definir las condiciones ambientales valorizadas para el asentamiento en la Bahía de Valparaíso.

\footnotetext{
${ }^{15}$ Bilbao Francisco (1823-1865) fundó con Santiago Arcos, la "Sociedad de la Igualdad" en 1850, a buena vista de la necesidad de "levantar la clase obrera, de organizarla con entera independencia de los partidos y de la política militante y de educarla en el conocimiento y amor de sus derechos". En ese mismo año fue excomulgado por la publicación de "Boletines del Espíritu", exiliado en 1851, se radica en Buenos Aires, donde muere en 1865. Cfr. FRANCISCO BILBAO, Héroe romántico de América, Gonzalo Fernández Meriggio, Casa Editorial de Valparaíso, Valparaíso 1998. (Nota: Hasta hoy no han sido repatriados los restos de Bilbao, Jorge Coulon Larrañaga (Inti Illimani), me señaló que en 1995 ubicó su tumba en el cementerio de La Recoleta en Buenos Aires, haciendo incluir su nombre en el libro de personajes ilustres que allí reposan).

${ }^{16} \mathrm{La}$ abstracción desde razones análogas a formalizaciones sociales es extremadamente abstracto, tenemos el "Falasterio" de Fourier, el "Paralelogramo" de Owen, o "Icaria" de Cabet. En el decir de Gravagnuolo...motivos de puntilloso realismo confundidos entre la más fragosa polifonía utópica"... en Cfr. HISTORIA DEL URBANISMO EN EUROPA (1750-1960) Benedetto Gravagnuolo, Akal Arquitectura, Madrid. 1991.

17 Cfr. Capitulo homónimo desarrollado por el autor en: "Sistematización de los factores humanos, económico físicos que concurren a la obsolescencia de los barrios de Valparaíso." Alvarez L., Mastrantonio, J. y de Nordenflicht, J. Proyecto DGIP-UCV, Código del Proyecto: 102.723-93, Informe Final.

Rectoría Académica, Dirección General de Investigación y Postgrado, Universidad Católica de Valparaíso.
} 
La Bahía de Valparaíso dispondrá de los dos recursos necesarios para la habitabilidad:

Recurso Hídrico: La Bahía de valorización original corresponde a una contenida dentro de la actual Bahía de Valparaíso, que se reconoce como Quintil. Esta unidad emplazada entre los antiguos morros de Artillería (Fuerte San Antonio) y Morro de la Concepción, disponía de tres importantes quebradas con disposición de agua dulce permanente, necesidad prioritaria para la travesía marinera de la costa chilena. Las Quebradas de Juan Gómez, nombre tomado del piloto de Saavedra (actual Carampangue), San Francisco, y Elías (actual Tomás Ramos).

Estos cursos de agua permanente, presentan tal condición por los niveles de pluviosidad presentes, apoyados por su orografía la que se comporta como un biombo que permitirá el desarrollo de un bosque esclerófilo inexistente en latitudes inferiores (excepto en bosques relictos). Éste se constituye en un apoyo importante para los cursos de agua, ya que regula la escorrentía, la vegetación incrementa la capacidad de retención hídrica al interior de las cuencas ${ }^{18}$, su régimen es pluvial, haciéndose crítico el período de estación seca larga (estivo), La bahía de Quintil respecto de este recurso era una excepción.

Valparaíso dispone de un bosque nativo esclerófilo exuberante. Aquí está la segunda condición básica para el desarrollo del asentamiento en Valparaíso: el recurso energético. Especies como: Litre, Boldo, Peumo, Pataguas, Arrayán, Quillay coexistían con unidades de palmas chilenas (Jubaea Chilensis), un paisaje sobre el cual se sustenta el topónimo de Valparaíso ("Valle del Paraíso").

Las condiciones oceanográficas manifiestan una corriente permanente en sentido norte, asociado al viento predominante con dirección Suroeste (SW), que terminan cerrando las desembocaduras de los esteros y quebradas, una vez terminado el período invernal, creando barras características de los cursos de agua que tienen su origen en la cordillera de la Costa: a esta condición se asocian las inundaciones permanentes.

De esta forma las condiciones del soporte original, obligaban a replegarse de los riesgos por inundación creados por condiciones hidrológicas y litorales: Marismas (marea alta), Sicigias (marea alta), y Cursos de agua. Todas estas "líneas de inundación" e "inundación por afloramientos" definirán las áreas "no urbanizables". A este riesgo se une un afán conservacionista pues en estas unidades geográficas, se disponen de dos de los recursos necesarios para la habitabilidad: agua dulce y sal.

El agua de bebida. La revolución de la distribución restringuida a la colectivización a través de las redes, y degradación de las condiciones naturales de los cursos de agua.

\footnotetext{
18 ... cuando todas las quebradas de Valparaíso se desprendía agua en abundancia, alimentando por lo mismo una vegetación exuberante en las colinas del extenso anfiteatro. Después, las corrientes que también suministraban agua para la bebida, disminuyeron, por la sencilla razón de haberse tolerado el corte y destrucción de los árboles que cubrían las quebradas. Por último, se toleró también el establecimiento de una multitud de hornos de tejas y ladrillos, que ayudaron eficazmente al daño... En: Hernández, R. C. 1927.
} 
Guillermo Weelright, fue el que implementó en 1850 el servicio de agua por cañería en Valparaíso; comenzó sus trabajos en la quebrada San Agustín, construyendo allí una captación y un estanque, y tendió cañerías de fierro fundido por La Planchada (actual calle Serrano), y por San Juan de Dios (Condell) hasta la calle del circo (Edwards).

Hacia 1876 Jorge Lyon y Eugenio Kammerer proyectaron y ejecutaron elevar agua desde El Salto en Viña del Mar.

El usufructo de las Quebradas de Valparaíso y de los acuíferos del plan, manifestado en "norias" cuya producción es de dudosa calidad $^{19}$, paulatinamente es abandonado a favor de los grandes proyectos hidráulicos para captar el agua de bebida, dejando atrás el traslado ambulante de este recurso ${ }^{20}$; esta época termina con las grandes obras de acopio del Embalse de Las Cenizas y el Embalse de Peñuelas.

En 1887 se encargó a Don Jorge Lyon y al ingeniero Ismael Rengifo, las obras para el embalse Peñuelas, las que comenzaron en 1889, y terminaron en el año 1900.

"Contando con un servicio de agua potable pura y otros requisitos, por decreto supremo 947 del 3 de Julio de 1930, Valparaíso fue inscrito en la oficina Sanitaria Panamericana como Puerto Limpio Clase A de acuerdo con lo dispuesto en el artículo XXXI del código Sanitario Panamericano"21.

El saneamiento del agua de bebida, genera una subutilización de las quebradas, entrando en un proceso de abandono respecto de su recurso hídrico; posteriormente se utilizaran para acceder a las sucesivas terrazas de Valparaíso, desarrollándose un proceso urbano por acreción siguiendo el principio: Quebrada - Ladera - Cima. Este principio de acreción se repetirá sucesivamente en tres terrazas de abrasión marina; ubicadas a 40, 110, 200 metros sobre el nivel del mar.

Estos procesos de urbanización cíclicos, obligarán el saneamiento de los cursos de agua (Fig. No1); la principal acción de este tipo la efectúo hacia 1860 don Juan Melgarejo, y bajo su gestión se desarrolló un vasto programa de saneamiento que consideró el mejoramiento y limpieza de los cauces de las quebradas y esteros, encauzándolos, y el adoquinado de las calles principales de la ciudad (Serrano, La Planchada, San Juan de Dios- del Cabo).

19 "...He sabido que algunos señores ingleses dicen que el aqua de que se proveen los buques en mi casa es muy mala y se corrompe en poco tiempo; para que el público pueda juzgar de la injusticia con que se profieren léase certificado de Manuel Piñeiro".. Inserción del Comerciante portugués Francisco Alvares, en; cfr: El Mercurio de Valparaíso 19 Septiembre de 1827.

20 ".-.Lo que sobre todo llama la atención del norteamericano recién llegado son los aguateros que con sus mulas acarrean el agua de manantial de las quebradas y surten todas las familias. La mula lleva al lomo dos pequeñas barricas, suspendidas una a cada lado sobre una armazón de madera hecha con ese objeto; y el aguador va sentado en ancas moviendo sus piernas desnudas, primero una y después la otra como en el acto de espolear. Usan sombrero basto de forma cónica, bien ajustado a la cabeza, camisa con mangas arremangadas hasta arriba del codo, delantal de cuero, semejante al de los herreros y un ancho pantalón que les llega hasta debajo de las rodillas. Cuando el aguador se detiene para desatar una de las barricas, apoya la otra con la vara que lleva para ese objeto, evitando así que se le vuelque la montura. El agua vale un real la carga". William S. W. Ruschemberg (1831) en Hernández, Roberto, op. Cit.

${ }^{21}$ Aguirre Echiburu, Luis "EL LIBRO DE VALPARAÍSO", Valparaíso. 1945. 


\section{El encauzamiento y abovedamiento de las quebradas en Valparaíso}

Las unidades hidrológicas de la Bahía de Valparaíso, son abastecidas sólo por precipitaciones, reduciéndose drásticamente su caudal en el verano. El aumento de población durante el siglo XIX, y la habilitación de nuevas formas de acceder al agua de bebida, aceleraron los procesos de deterioro e insalubridad de estos espacios abiertos.

Proliferó a partir de 1827, y no exenta de problemas dado el desarrollo espontáneo de la ciudad 22 , la necesidad de encauzar, corrigiendo algunos trazados para iniciar el abovedamiento: fue un trabajo de desarrollo paulatino y de esfuerzo colectivo (Fig. N02).

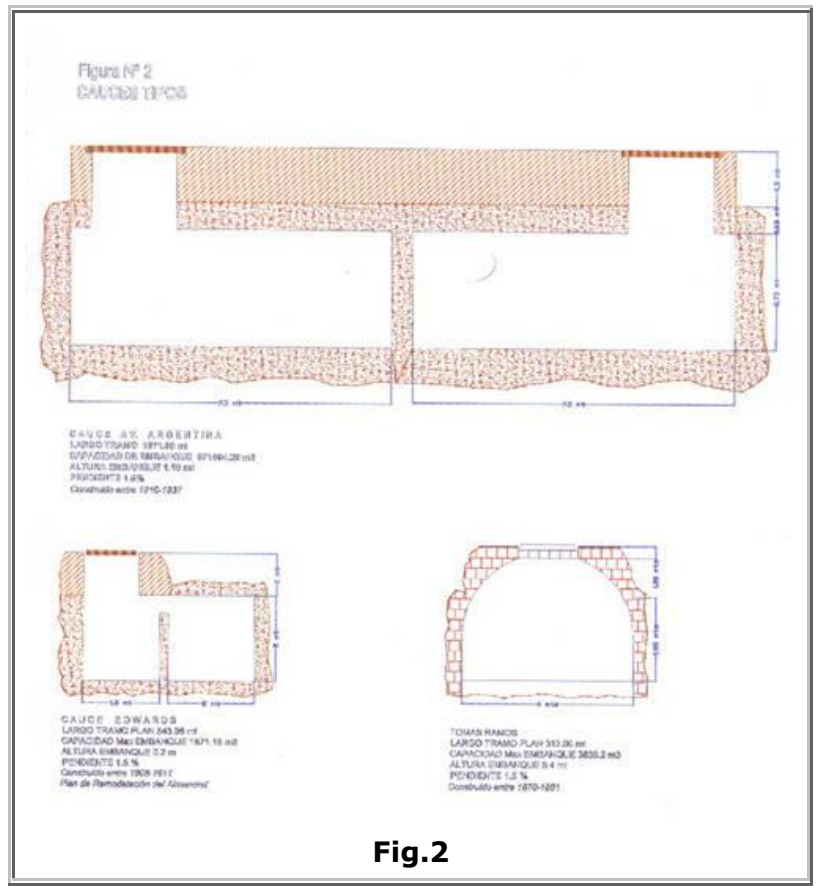

22 ...Cada hijo de vecino levanta su pared, fabrica un pretil y refacciona el daño que le ocasionó el temporal que asoló la ciudad, a quien le cedieron dos mil pesos para restablecer las pérdidas, hizo unos pocos puentes de madera en los principales zanjones por lo pronto, y por lo largo. Cada uno es dueño de su casa y su frente y piensan poner un derecho de pasaje a los traficantes. En la plazuela de la Matriz y dentro de la Plaza se han hecho dos pretiles de cal y piedra, sin consultar el derecho público, Don Manuel Blanco está empedrando la calle de los baratillos, aunque ahogue a los vecinos del frente. En la quebrada de San Juan de dios, arbitrariamente se han hecho dos pretiles, sin consultar si es o no terreno propio; de suerte que a la vuelta de diez años todo debe ser edificios sin calles y sin bahía, porque los cerros se están trasladando a ella"... EL MERCURIO DE VALPARAÍSO No 26, 7 de Diciembre de 1827. 
Con el modelo de "excreción" subterráneo la administración de la ciudad logra sintetizar, en una única fórmula, tres aspectos básicos de la ciudad decimonónica: la tecnología (como instrumento básico de la lógica productiva), los preceptos médicos (como legitimación del modelo) y la construcción de un precedente para tornar invisibles todos aquellos flujos y actividades no deseadas en el seno del cuerpo social dominante.

Es, como explica Mumford L. (1971), una experiencia que está en el centro mismo de la mecanización del universo y que se define como la victoria del pensamiento racional ${ }^{23}$.

\section{De los abovedamientos a la generación de los Espacios Públicos: la línea de costa}

El borde mar como límite natural es la constante dificultad de desarrollo urbano que tiene Valparaíso, desde su origen como caleta hasta la gran remodelación del primer cuarto de este siglo. La estrechez entre el mar y los cerros, dejando una escasa franja de territorio que conformará el $\operatorname{Plan}^{24}$, obligará periódicamente a generar rellenos sobre la línea de costa, para ampliar las áreas planas.

La materialización de esta consolidación del borde costero se realizó en varias etapas (Fig. N03), identificándose en el periodo 1848 hasta 1885 la más relevante desde el punto de vista de la creación de espacio público; la Av. Brasil, (Figs. N04).

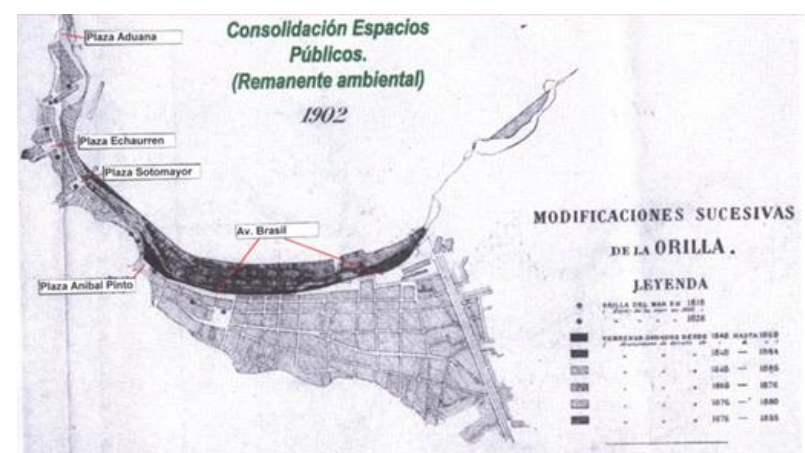

Fig.3.- CONSOLIDACIÓN LÍNEA DE COSTA Y DE LOS ESPACIOS PúBlicos. A medida que se le gana espacio al mar, los remanentes ambientales comienzan a estructurarse para incorporarse al área consolidada de la ciudad. Fte.: J. B. Mannheim, Dir. Obras Portuarias 1876, publicado por Recaredo Santos Tornero, 1884.

${ }^{23} \mathrm{cfr}$. Una buena referencia respecto de esta idealización la constituye el artículo de: Francisco de Assis da Costa, "La compulsión por lo limpio en la idealización y construcción de la ciudad contemporánea. Gestión residual en Barcelona 1849-1936", en Scripta Nova Revista No 69, 1 de agosto de 2000. Revista Electrónica de Geografía y Ciencias Sociales. Universidad de Barcelona [ISSN 1138-9788].

24 ..."Hallábase situada la casa Alsop al borde de la antigua quebrada o barranco del Almendro, en un sitio inmediato al que ahora tienen la Bolsa y los Bancos que la circundan. Esa era la única vía que utilizaba el comercio de alta talla, nacional y extranjero, pues la calle de Cochrane no había sido aún regalada a la ciudad por las basuras, las arenas y las olas"...en Hernández, Roberto. Op.cit. 


\section{RUVSTADE URBANISMO
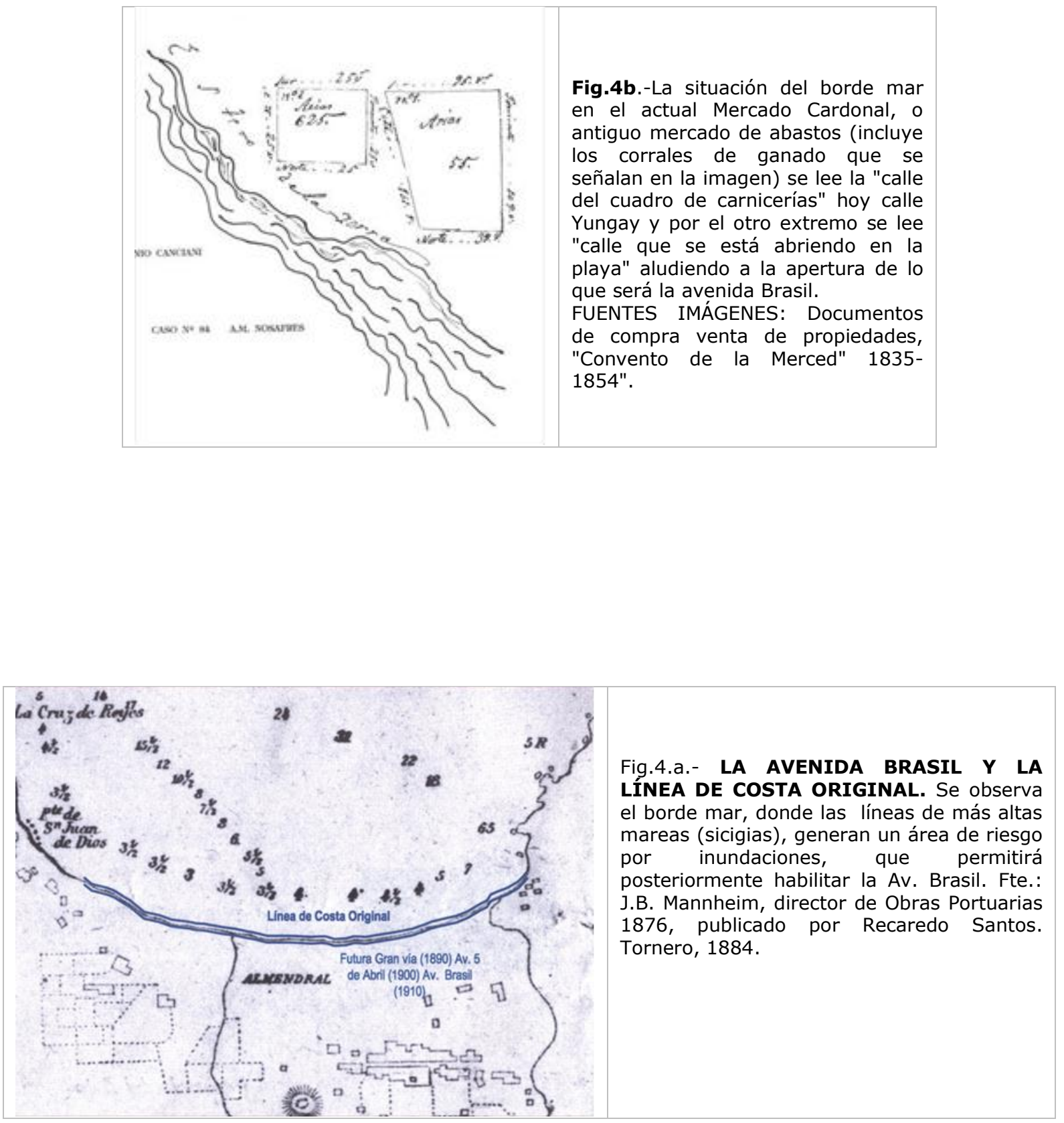
De este modo la consolidación del borde costero se produce en la Bahía de Valparaíso hacia 1885, cuyo principal aporte lo constituye la Av. Brasil entre Plaza Aníbal Pinto y Av. Argentina ${ }^{25}$ : la superficie incorporada en este espacio público, que alcanza a 6,3 Há, es proyectada como "Gran Vía". Es precisamente este espacio el que se nos presenta, en esta primera aproximación planimétrica ${ }^{26}$ como el de mayor aporte desde el punto de vista de los remanentes ambientales con 6,3 Há de un total de 14,68 Há originadas por este factor.

A esto hay que agregar nuevos accesos viales como la Av. 5 de Abril ${ }^{27}$, los ejes de la Calle Blanco ${ }^{28}$ y la Avenida Errázuriz ${ }^{29}$.

En el extremo poniente del puerto, hacia principios de la década de 1870, existía una sola calle que había sido ganada al mar, la calle del Cabo, actual Esmeralda, con edificios que limitaban hacia el sur con el cerro. En esta misma década se proyectaba hacer otra calle que partiría de la Estación Bellavista para terminar en el Muelle de Pasajeros, también fundada sobre terrenos artificiales ganados al mar. Esta calle se constituiría en la calle Nueva de Blanco ${ }^{30}$. Durante el período de los años 1875-76 se realizaron finalmente las defensas definitivas (para ese período) del malecón paralelo a la calle Blanco ${ }^{31}$, generando una conectividad de mayor eficiencia en el sentido orienteponiente que aún se mantiene en la estructura urbana de Valparaíso.

${ }^{25}$ El malecón de piedra que se ha construido en ambas riberas del estero de las Delicias (antiguo nombre dado a la Av. Argentina), es una de aquellas obras que solo se llevan a cabo en pueblos tan decididos como Valparaíso por el adelantamiento local. Los miles que se hallan invertido en el no son para nosotros los que agradecen su importancia; es el beneficio que recibe la población lo que debe, considerarse para juzgarlo, así como los buenas y malas obras de un gobierno son las que deben ponerse en la balanza de la justicia para que decidan de la buena o mala opinión de que debe gozar.

Ha pasado la municipalidad y el vecindario para llevar a cabo aquella obra, no deben considerarse estériles desde que vemos asegurado de una manera formidable, indestructible aquella parte de la población, que estaba amenazada de inundación con las frecuentes crecidas del estero. Parecerá tal vez extemporáneo que nos ocuparemos de considerar la importancia que en si tiene el malecón de las Delicias, pero nosotros daremos que es de mucha oportunidad, pues tratamos nada menos que convencer que de convencer a algunos espíritus egoístas que consideren como un gravamen a sus intereses que se les haga obligado a construirse la parte del malecón que en correspondencia, además de esta la otra no está aún concluido, enteramente, y deseamos que los propietarios quienes corresponde terminarlo percaten de la necesidad de darle cima. EL MERCURIO, Jueves 29 de Abril 1858.

${ }^{26}$ Las fuentes de los planos son: plano de 1854 de Plano Topográfico de la Ciudad y Puerto de Valparaíso. Levantado en 1848 por D. Ramón Salazar. Publicado por "El Mercurio" Santos Tornero y Cía., reformado y Aumentado por el autor, Agosto de 1854, escala 1:4.000; plano de 1876 de Plano Topográfico de la Población Baja y Alta de la Ciudad de Valparaíso, dedicado al Ex-Intendente de la Provincia Don Francisco Echaurren, por J.B. Mannheim, director de Obras Públicas, 1876, escala 1:2.000; plano de 1884 de Nuevo Plano Topográfico de la Ciudad de Valparaíso, publicado por D. Recaredo Santos Tornero, dedicado al municipio en 1884, escala 1:4.000; y plano de 1908 de Plano del Instituto Geográfico Militar levantado en 1908 , escala 1:25.000. También se utiliza planimetría actual como fotografías aéreas y su restitución, escala 1:5000, del vuelo FONDEFF 1996.

27 Reconocido tempranamente por la literatura de crónica y recopilación histórica, cfr. UGARTE, J. de D. Historia de Valparaíso, 1910, pág. 26.

${ }^{28}$ Idem, pág. 42.

29 Sociedad Editora Internacional Baedeker de la República de Chile, Imprenta y Litografía América, Santiago, 1910, p.236.

30 BÓRQUEZ, Juan et alt. Los terrenos ganados al mar en el "Barrio Puerto" de Valparaíso. Consideraciones Geográficas-Históricas, Seminario de Titulación para optar al título de profesor de Historia, Geografía y Ciencias Sociales, Instituto de Geografía, Universidad Católica de Valparaíso, Valparaíso, 1983.

${ }^{31}$ Idem. , pág. 46. 
El tendido de la línea del ferrocarril logra unir finalmente el Puerto a través de la estación de la Bolsa ${ }^{32}$ con la Estación Bellavista, constituyendo ésta y su entorno un importante lugar de sociabilidad que se conocía como Paseo del Malecón ${ }^{33}$, hoy incorporado como parte de la faja del ferrocarril y de la estación Puerto, construida hacia 1927.

Sobre el financiamiento de los espacios públicos generados por degradación ambiental se puede avanzar la hipótesis de que en su mayoría fueron absorbidos por el Fisco y que sólo en situaciones particulares, como la del Ferrocarril, intervinieron los privados: esta idea se apoya en que la participación de capitales de, por ejemplo, las sociedades anónimas en trabajos urbanos, era mínima en comparación con otras áreas de mayor interés ${ }^{34}$, a notar, la administración local crea hacia mediados del s. XIX el cuerpo de "Policía Urbana" encargada de las obras de equipamiento público.

\section{Esteros y Cauces en la creación de nuevos espacios públicos}

El desarrollo más fructífero desde el punto de vista del aporte urbano, lo constituyen la generación de las Plazas y los accesos a los cerros de la bahía de Valparaíso, una vez que el proceso de abovedamiento (Cuadro $\mathrm{N}^{0} 1$ ), consistente en la construcción de obras de infraestructura para encauzar las quebradas y su paso por la ciudad, posteriormente sobre ellos se construye losas o soluciones mixtas de pretiles y arcos cubriendo totalmente los cauces.

\footnotetext{
${ }^{32}$ Idem., pág. 87.

33 UGARTE, op. cit., pág. 66.

34 Véase el análisis desde la historia económica en CAVIERES, E. "Estructura y Funcionamiento de las sociedades comerciales de Valparaíso durante el siglo XIX (1820-1880)", Cuadernos de Historia, Universidad de Chile, n4, 1984, especialmente el cuadro de la pág. 74.
} 


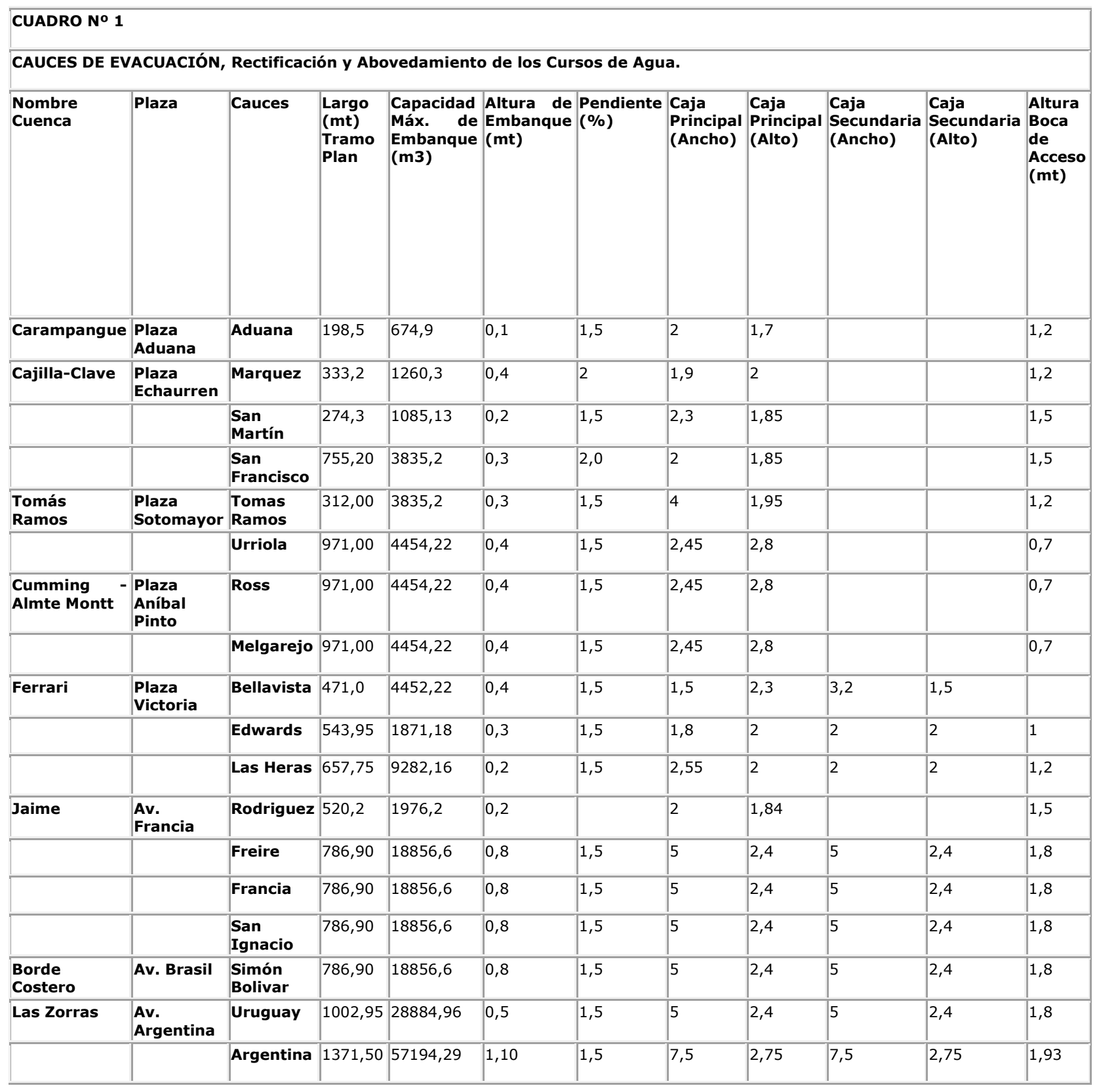


Como se señaló al referirnos a las condiciones ambientales originales, las áreas de inundación constituyen una reserva forzada para la consolidación de los espacios públicos, a saber:

El lecho y la caja de inundación expresada en metros de ancho, se constituyeron en la vía de interconexión del plan con las terrazas y cerros de la bahía de Valparaíso. (Figs. N05, a y b).
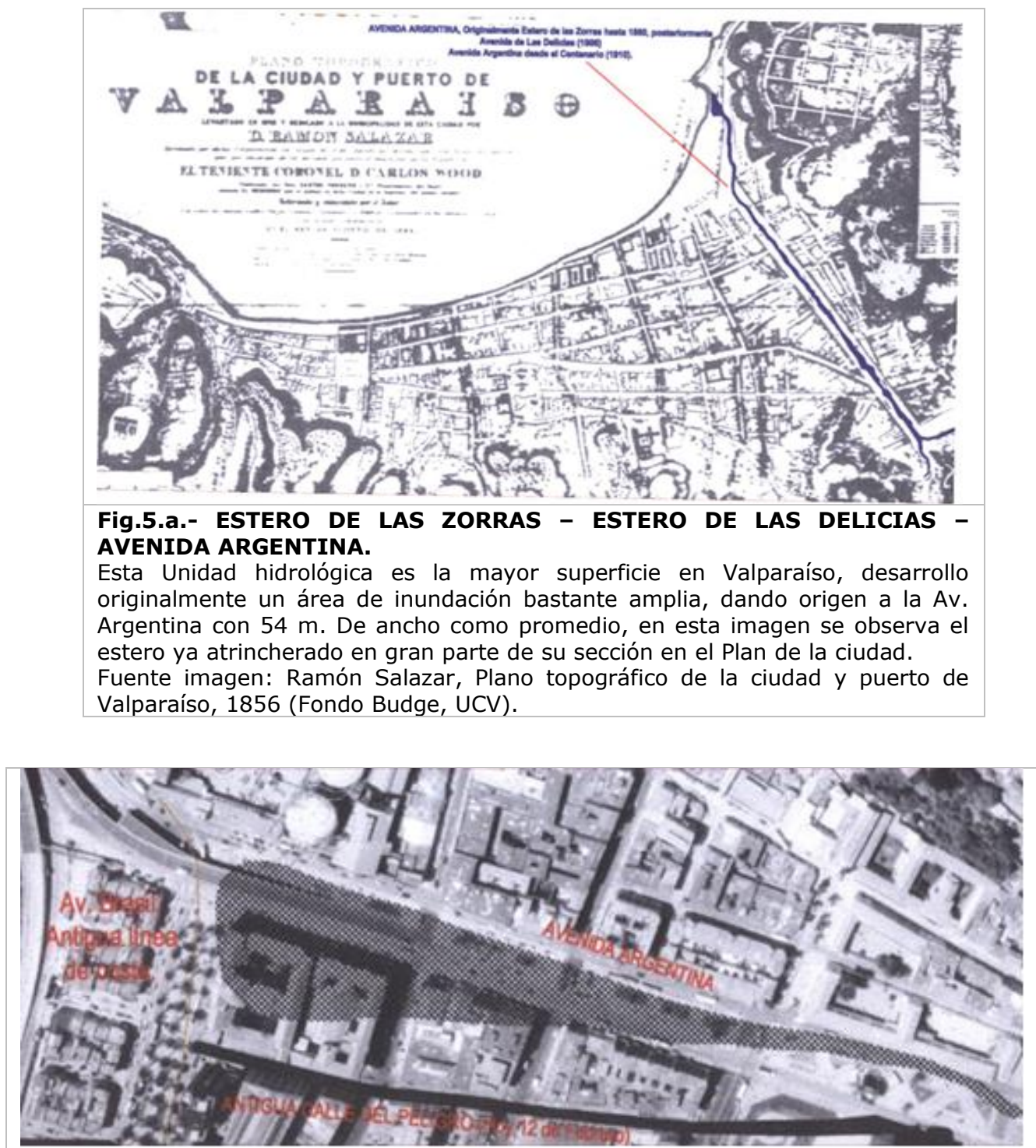

Fig.5.b.- En la imagen se observa el área de inundación producto de la barra natural generada en el borde-mar, la inundación se extiende al sur producto de la pendiente al norte (pie de cerro). Al sur se originó la actual calle 12 de Febrero, originalmente "calle del Peligro" (producto de las inundaciones), la Av. Brasil corresponde al espacio público producto del área de inundación de las mareas, generando una barra en la desembocadura del estero. Fuente plano: Fotografía aérea Fondef 1994, con información de archivos "Convento de la Merced" entre 1830 - 1845. 
Las áreas de inundación en las desembocaduras, aumentadas, producto de la corriente y las barras litorales, terminarán convirtiéndose en las plazas de Valparaíso (Fig. N6).

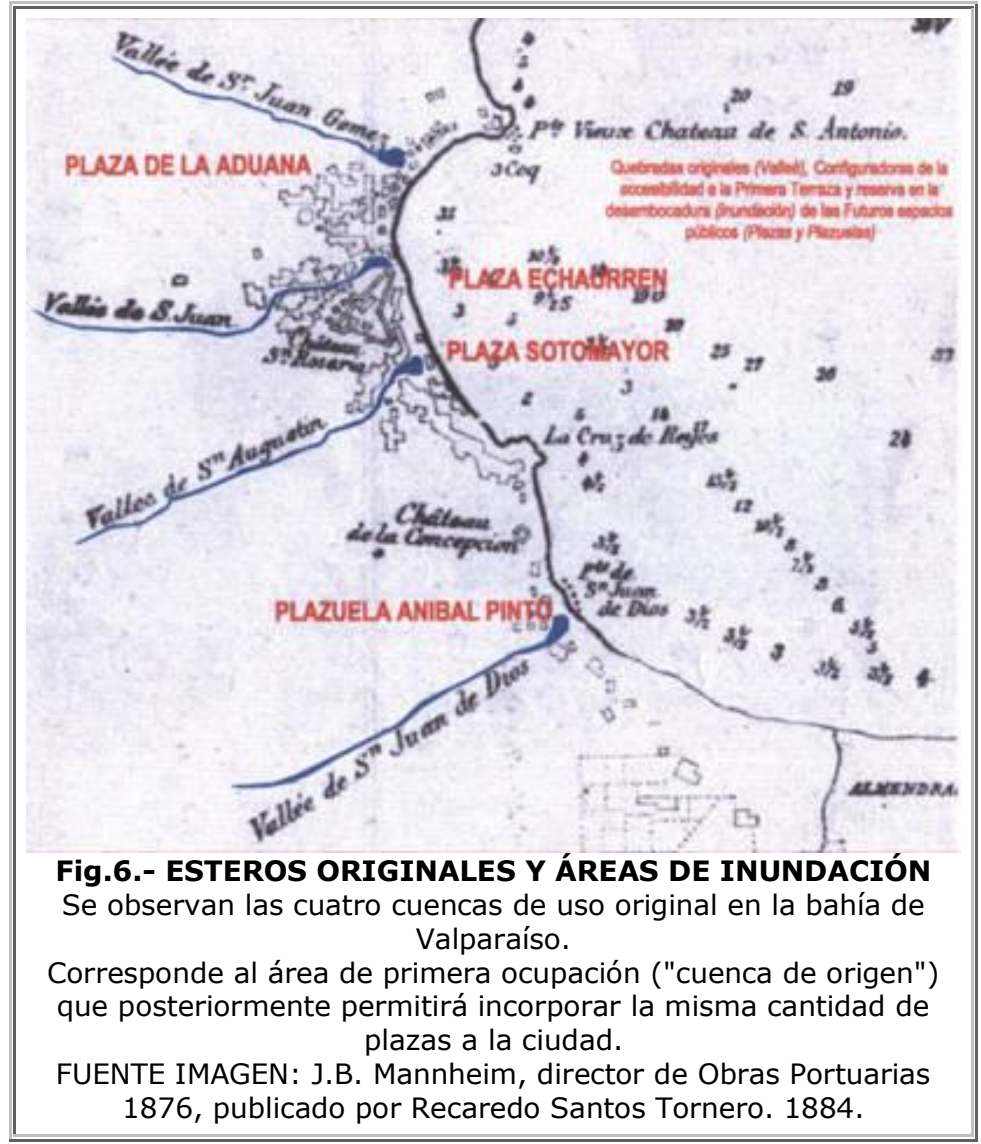

De este modo se configura una unidad de acceso que se inicia o remata con las plazas. Éstas se constituyen originalmente en espacios baldíos o eriazos y se constituyen en reserva para comienzos del siglo XX, las primeras transformaciones de estas unidades a través de las arborizaciones y la instalación de mobiliario, producto de un sistemático abandono de las actividades que albergaban, entre ella mercados de abastos, corrales, circos, espectáculos urbanos, actividades castrenses (retretas), actividades religiosas y pérgolas, entre otras. 
Del total de espacios públicos generados (Cuadros $\mathrm{N}^{0} 2$ y $\mathrm{N}^{\circ} 3$ ) en el Plan de la Ciudad de Valparaíso y que constituyen los espacios públicos más relevantes, el $78 \%$ se origina a través de lo planteado en este artículo; degradación ambiental, que posteriormente obligará a abovedar cerrando los cursos de agua y entregando a la ciudad nuevo espacio, esencialmente público. El $22 \%$ restante constituyen unidades de parques originalmente privados como el Jardín Abadie - hoy es el Parque Italia-, y el Jardín del Litre, hoy convertido en Parque; estos dos últimos son los que mejor se asemejan a las "plazas" chilenas, pero en Valparaíso son "Parques", dejando el concepto de Plaza y Plazuela para la unidad tipo española, es decir eriazas o de gran explanada, que circunstancialmente se arborizaron y adquirieron mobiliario en los afanes de vísperas del primer Centenario de la República.

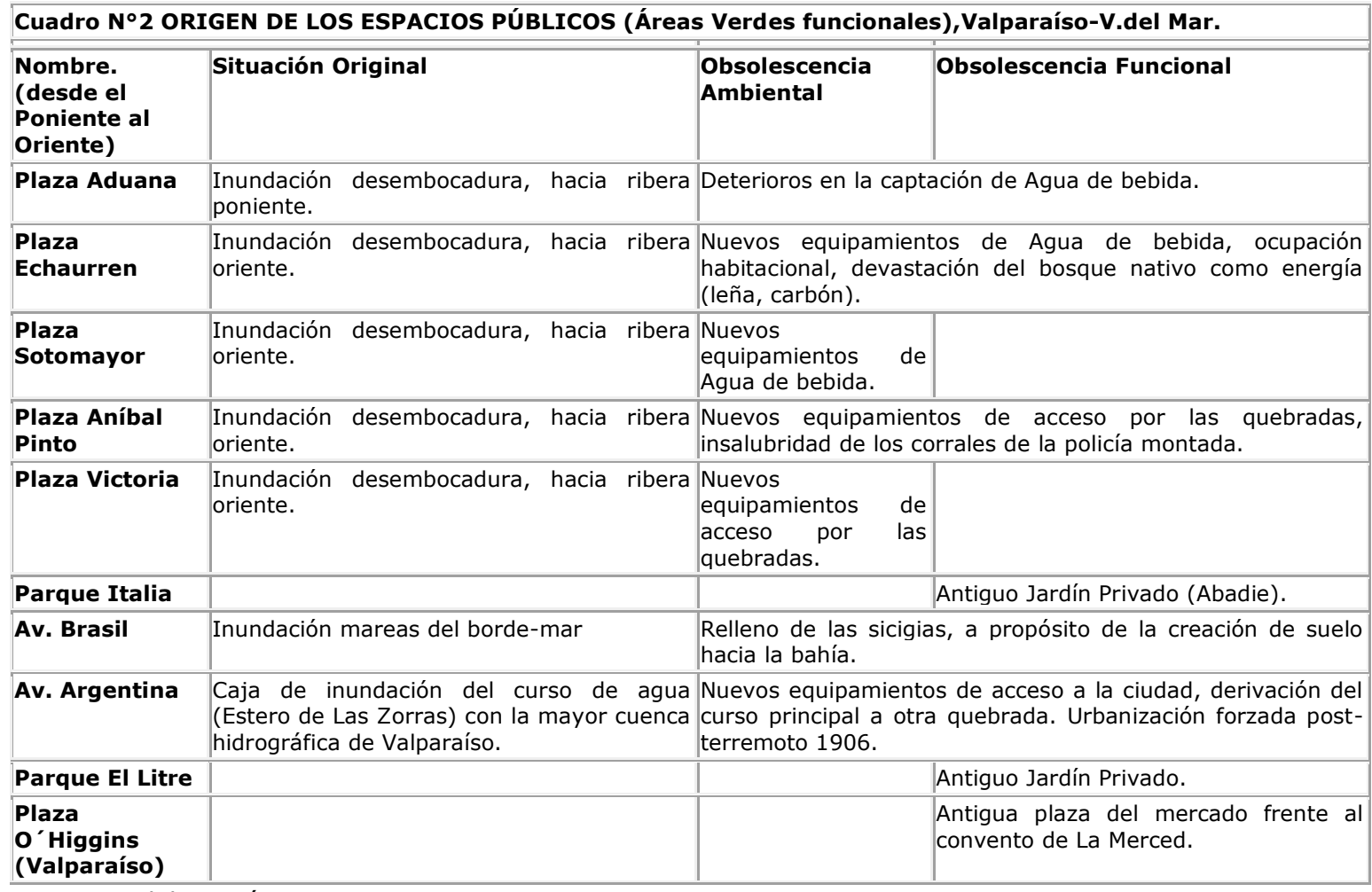

FUENTE: Elaboración Propia, DGIP-UCV 1993. 


\begin{tabular}{|c|c|c|c|c|c|c|}
\hline CUADRO NO 3 & & & & & & \\
\hline \multicolumn{7}{|c|}{$\begin{array}{l}\text { SITUACIÓN AMBIENTAL DE LOS CURSOS DE } \\
\text { AGUA EN VALPARAÍSO. }\end{array}$} \\
\hline $\begin{array}{l}\text { Nombre } \\
\text { cuenca }\end{array}$ & Plaza & $\begin{array}{l}\text { Superficie } \\
(\mathrm{m} 2)\end{array}$ & \begin{tabular}{|l}
$\begin{array}{l}\text { Altura } \\
\text { origen } \\
\text { (msnm) }\end{array}$ \\
\end{tabular} & $\begin{array}{l}\text { Distancia al } \\
\text { Borde Mar } \\
\text { (m) }\end{array}$ & $\begin{array}{l}\text { Superficie de } \\
\text { Inundación } \\
\text { Original }(\mathrm{m} 2)\end{array}$ & $\begin{array}{l}\text { Superficie Espacio Público } \\
\text { creado }(\mathbf{m} 2)\end{array}$ \\
\hline Carampangue & Plaza Aduana & 336489 & 183,6 & 1283,1 & 6636,0 & 5593,0 \\
\hline Cajilla-Clave & $\begin{array}{l}\text { Plaza } \\
\text { Echaurren }\end{array}$ & 1937786,42 & 319,5 & 1669,4 & 4633,5 & 2269,7 \\
\hline Tomás Ramos & $\begin{array}{l}\text { Plaza } \\
\text { Sotomayor }\end{array}$ & 1148820,43 & 342,2 & 2287,88 & 3034,1 & 13995,9 \\
\hline $\begin{array}{l}\text { Cumming - } \\
\text { Almte Montt }\end{array}$ & $\begin{array}{l}\text { Plaza Aníbal } \\
\text { Pinto }\end{array}$ & 2529054,29 & 453,2 & 2789,04 & 4813,3 & 3509,4 \\
\hline Ferrari & Plaza Victoria & 1169705,04 & 350,2 & 2647,4 & 13457,8 & 17953,4 \\
\hline$*$ & Parque Italia & * & * & * & no existe & 14114,4 \\
\hline Jaime & Av. Francia & 3843035,74 & 512 & 4183,54 & 23546,2 & 14398,09 \\
\hline Borde Costero & Av. Brasil & * & * & * & 78136,91 & 63476,8 \\
\hline * & $\begin{array}{l}\text { Plaza } \\
\text { o'Higgins } \\
\text { (Valparaíso) }\end{array}$ & * & * & * & no existe & 22058,1 \\
\hline Las Zorras & Av. Argentina & 10768519,72 & 506,7 & 6060,7 & 51993,58 & 34683,4 \\
\hline$*$ & Parque EI Litre & $*$ & * & * & no existe & 2200,7 \\
\hline \multicolumn{7}{|c|}{ FUENTE: Elaboración propia } \\
\hline \multicolumn{6}{|c|}{ a partir de Cartas Topográficas de Valparaíso, Escala 1:5000, Restituidas desde aerofotos } & 18 Há \\
\hline vuelo FONDEFF 1 & 1996.- & & & & & \\
\hline
\end{tabular}

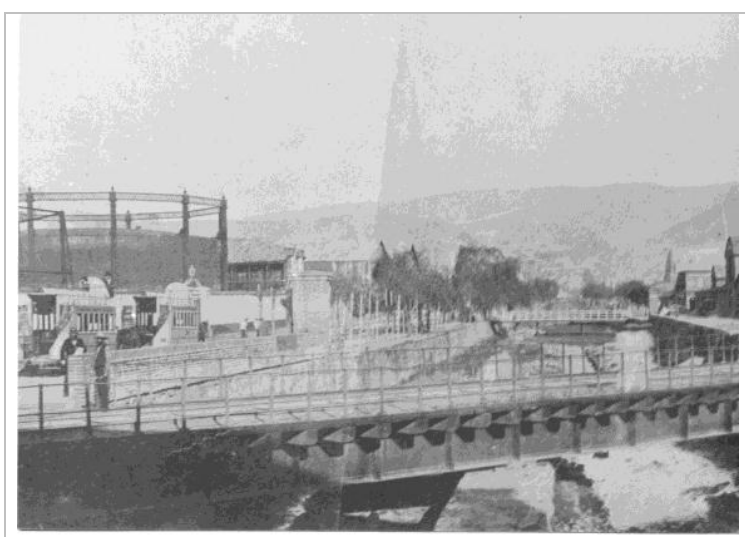

AVENIDA ARGENTINA 1900, Cauce del Estero de las Zorras Expuesto, con puente ferroviario y de tranvías.

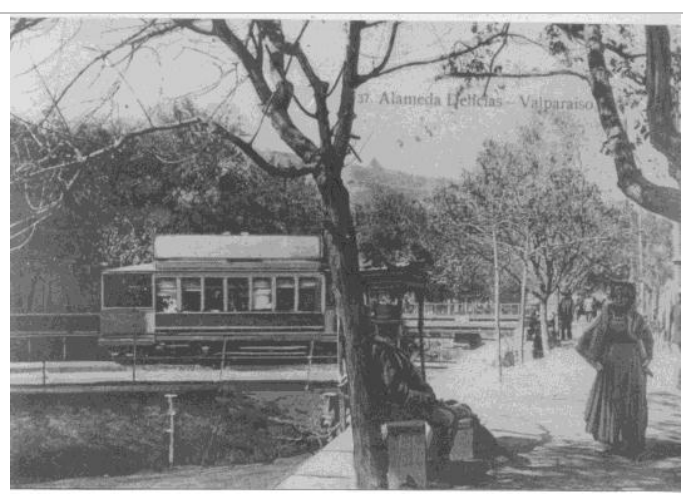

AVENIDA ARGENTINA 1910, Cauce del Estero de las "Delicias", renonbrado homologandolo a la Avenida de Las delicias de Santiago. 


\section{REVISTA DE URBANISMO

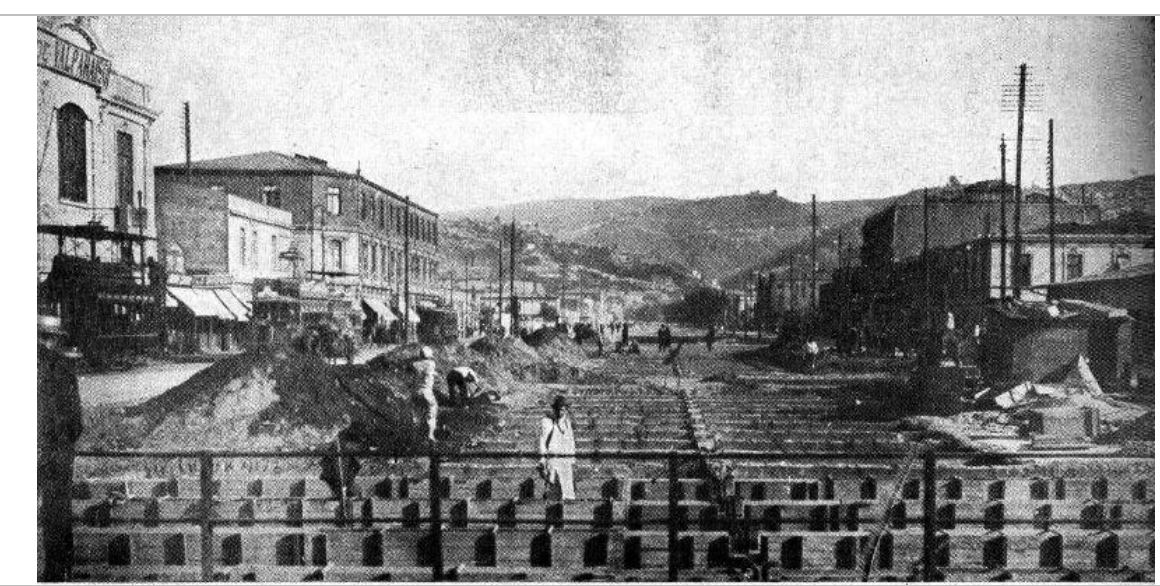

AVENIDA ARGentinA 1913, Cauce del Estero de las "Delicias". Comienzo del abovedamiento en el tramo Quillota-Pedro Montt.

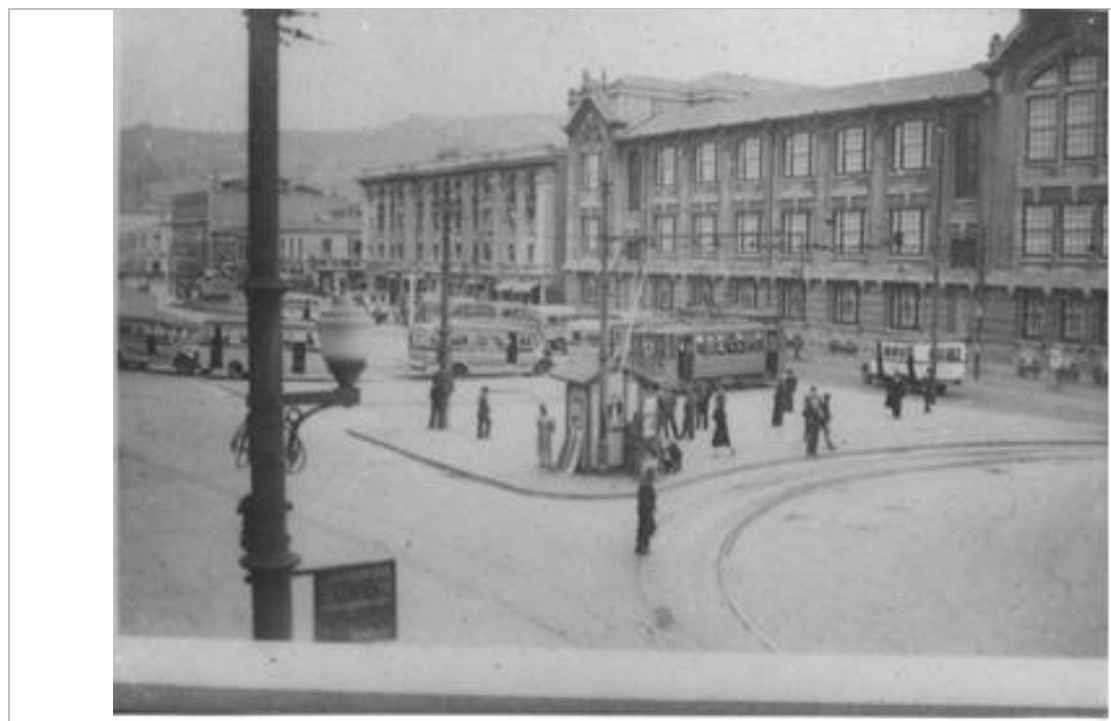

AVENIDA ARGENTINA 1932, abovedamiento completo desde Santa Elena. Gran envergadura de espacio Público en toda su extensión, en proporción al desarrollo histórico de estos, en la ciudad de Valparaíso. 


\section{Conclusiones}

La ciudad que forjó la República presentó cambios significativos; como puerto, permanentemente accedió al conocimiento y la tecnología.

A mediados del s. XIX, el abovedamiento de los esteros de Valparaíso, es lo más cercano al sueño utópico de una ciudad subterránea, que atendiera específicamente a las necesidades de la evacuación de los flujos indeseables de la superficie original.

Esta necesidad trae aparejado un beneficio secundario, la creación de los espacios públicos de mayor significado para la ciudad.

Una ciudad sin fundación, desarrollada espontáneamente, adquiere de parte del entorno que originalmente le dio las condiciones básicas de habitabilidad, los espacios en los que no se pensó originalmente.

Respecto de la capacidad de la planificación física, para imponer un tipo de estructura, en Valparaíso sólo se manifiestan parcialidades y de dudoso resultado.

El desarrollo físico en Valparaíso está condicionado fuertemente por el despliegue de un espacio reticular, en donde la "red de cauces" fue la impulsora del proceso urbano moderno y contemporáneo, que se masificará con las redes de saneamiento, fundamentalmente las de agua.

El espacio areolar de la planificación tradicional en Valparaíso no es constatable ${ }^{35}$ : lo dominante es una "territorialidad reticular" ${ }^{36}$, con claros y precisos nodos de desarrollo urbano, y es la única forma de entender la abundancia de espacios intersticiales en la ciudad de Valparaíso.

\section{Referencias}

ALVAREZ, L.; NAVARRO, V., "Análisis geo-Histórico de espacio urbano del barrio del Almendral Valparaíso, entre la Av. Argentina y la Av. Francia, hacia 1835-1842", en Revista Geográfica de Valparaíso No 22-23, 1994.

ALVAREZ L.; MASTRANTONIO, J. y de NORDENFLICHT, J., Sistematización de los factores humanos, económico físicos que concurren a la obsolescencia de los barrios de Valparaíso. Informe final del Proyecto DGIP-UCV, Universidad Católica de Valparaíso,

\footnotetext{
${ }^{35}$ Aquí el debate sobre, Territorialidad, Redes y Debate Urbanístico, aparece como clarificador y validado ampliamente con el estudio de la red de cauces de Valparaíso. Cfr; Territorialidad, Redes y Debate Urbanístico, M. Isabel PAVEZ REYES, en revista DE Arquitectura, No 7, FAU. Universidad de Chile, pp. 10-13.

${ }^{36}$ Dupuy, Gabriel, El Urbanismo de las Redes, Colegio de Ingenieros de Caminos, Oikos-Tau, 1992.
} 
Vice Rectoría Académica, Dirección General de Investigación y Postgrado. Código del Proyecto: 102.723-93, 1993.

ALVAREZ L., MASTRANTONIO, J., Estudio y Diseño de un Plan de Manejo del Patrimonio Urbano de la Ciudad de Valparaíso. Informe final del Proyecto DGIP-UCV, Universidad Católica de Valparaíso, Vice Rectoría Académica, Dirección General de Investigación y Postgrado. Código del Proyecto: 102.723-99, 1999.

HERNANDEZ, Roberto C., Valparaíso, Imprenta Victoria, Valparaíso, 1927.

URRUTIA DE HAZBUN Rosa; LANZA LAZCANO Carlos, Catástrofes en Chile 1541-1992. Editorial La Noria, Santiago, 1993.

URTEAGA, Luis, "Miseria, miasmas y microbios. Las topografias médicas y el estudio del medio ambiente en el siglo XIX", en Geocrítica, Cuadernos Críticos de Geografía Humana, No 29, septiembre de 1980.

DUPUY, Gabriel, El urbanismo de las redes, Colegio de Ingenieros de Caminos, OikosTau, Madrid, 1992.

PAVEZ, María Isabel, "Territorialidad, redes y debate urbanístico", en revista De Arquitectura, No 7, FAU. Universidad de Chile, 1997.

DA COSTA Francisco de Assis, "La compulsión por lo limpio en la idealización y construcción de la ciudad contemporánea. Gestión residual en Barcelona 1849-1936", en Scripta Nova Revista No 69, 1 de agosto de 2000. Revista Electrónica de Geografía y Ciencias Sociales, Universidad de Barcelona [ISSN 1138-9788].

BÓRQUEZ, Juan, Los terrenos ganados al mar en el "barrio puerto" de Valparaíso. Consideraciones Geográficas-Históricas, Seminario de Titulación para optar al título de Profesor de Historia, Geografía y Ciencias Sociales, Instituto de Geografía, Universidad Católica de Valparaíso, Valparaíso, 1983.

CAVIERES, Eduardo, "Estructura y funcionamiento de las sociedades comerciales de Valparaíso durante el siglo XIX (1820-1880)", en Cuadernos de Historia, Universidad de Chile, N04, 1984.

GRAVAGNUOLO, Benedetto, Historia del urbanismo en Europa (1750-1960). Akal Arquitectura, Madrid. 1991.

AGUIRRE. Echiburu, Luis 1945. "El libro de Valparaíso", Valparaíso.

EL MERCURIO DE VALPARAÍSO, Revisión 1865-1860, Archivo Fondo Budge, Universidad Católica de Valparaíso. 